\title{
NOTES ON HEMILEUCA LUCINA HY. EDW. ${ }^{1}$
}

\section{By William ReifF.}

On the 19th of last June, while in the company of Dr. Arthur L. Reagh on a collecting trip to the neighborhood of Raymond, N. H., we came upon a swampy meadow where there was an abundance of Meadow-sweet (Spiraea salicifolia L.). Immediately my attention was attracted to these plants which harbored a large number of unknown caterpillars. Interested in the find, we looked further and found the same species on nearly every bush of the Spiraea. The caterpillars were partly in the second and partly in the third stage, feeding close together in large numbers and dropping to the ground upon being disturbed. They were so thickly distributed on the plants, that often entire twigs were covered with the larvae, giving the impression of strong swellings upon the twigs. According to our estimates, we must have seen more than 20,000 caterpillars in the locality, but owing to lack of proper receptacles, we could unfortunately collect only a small part for breeding.

Although the caterpillars resembled those of Hemileuca maia Drury very closely, we could not satisfy ourselves that they belonged to this species, for it seemed strange that all the maia females should have laid their eggs on meadow-sweet when there was close by an abundance of oak which is the favorite food of maia. We also searched the nearby oaks for Hemileuca caterpillars without result, but Dr. Reagh found some maia on oaks several miles further on which proved their presence in the locality. Our caterpillars could therefore hardly be maia, for this species would have no necessity of laying its eggs on plants other than oaks. As already mentioned, our caterpillars were very similar to those of maia, and like them were black in the youngest stage, but distinguishable by a strong brilliancy, best compared to black stove-polish. The appearance of the older caterpillars was exactly like that of maia, except that all had a sharply defined white stripe above the feet, which is absent or faint in maia. In spite of plentiful and regular feeding the size of the growing caterpillars remained always less than that of maia. Pupation occurred on the

\footnotetext{
1 Contributions from the Entomological Laboratory of the Bussey Institution, Harvard University. No. 13.
} 
surface of the ground under dry leaves, without the preparation of any sort of a cocoon. The cremaster of the pupa is composed of about twenty-five strong brown spines with curved apices (see figure). In other respects, the form and color of the pupa are the same as those of maia; the size of lucina, however, always remains less. The first moths emerged from their pupae on the 2nd of September, and proved to be two males of Hemilerica lucina Hy. Edw. The first females emerged on the 4th of September, and the period of emergence extended almost through the entire month, the last adults appearing on September 28. In all

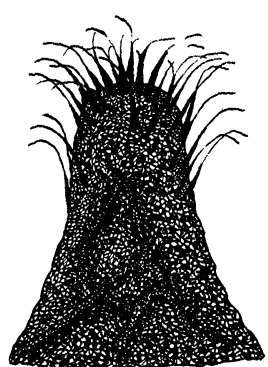

Fig. 1. Cremaster of Hemileuca lucina $\mathrm{Hy}$. Edw. sixty-three moths were obtained, in the proportion of $2: 1.3$ or about twice as many males as females. No parasites were obtained although six pupae died.

Henry Edwards states in his description of the form lucina (Entomologica Americana, Vol. II, No. 1, p. 14, April 1886) that the white band which encloses the discal spot is of equal width across the entire wing. This is not the case, however, as this character is the one which shows the greatest range of variation. I have before me a large number of specimens in which the discal spot is bordered with white only near the fore and hind margins, the white being so much reduced in size that it is divided into two parts by the spot. The most extreme form, of which I have one male and one female specimen, has the white band wedgeshaped and pointed toward the discal spot, above which it shows only as a slight light shadow. Since such extremes of variation in the direction of aberrations undoubtedly deserve names, I propose the name $a b$. obsoleta for this form of $H$. lucina with the following diagnosis:

Ab. obsoleta m.: alis ant. fascia candida plus minusve obsoleta. Types 1 $\sigma^{\top}, 1$ ㅇ, in the collection of the Bussey Institution.

The white band varies in another direction also, and both on the fore as well as on the hind wings. The white band may become cream yellow for its entire extent, the black ground color becoming at the same time changed to a gray, perhaps through some albinistic 
tendency. The most typical specimens of this aberration are females, as all the males of this form which I have seen show transitions to the type. I propose the name $a b$. lutea for this yellow form with the following diagnosis:

Ab. lutea m.: alis ant. et post. grisescentibus, fascia lutea nec candida. Types, two $\sigma^{\top} \delta^{\top}$ (transitions), two 우 우, in the collection of the Bussey Institution.

There is also a noteworthy male specimen, which has extraordinarily strongly developed veins, which are of a blackish green-brown color. The veins are irregularly marked with small greenish-brown specks along their entire extent. I am inclined to believe that the pupa from which this specimen developed was supplied with too great a quantity of lymph which enlarged the veins abnormally at the time of emergence, and later penetrated in the form of minute drops through the vein to the surface of the wing.

I treated a small percentage of the fresh pupae (10 specimens) with cold, exposing them to a temperature of $-3^{\circ} \mathrm{C}$. for seven consecutive days. From these seven moths emerged, three of the pupae dying. Of the emerging moths $\left(6 \sigma^{\top} \sigma^{\top}, 1\right.$ ㅇ $)$ the wings of two males did not expand, but the others developed to the normal size. One male was a typical $a b$. obsoleta, the female was the typical $a b$. lutea. The color pattern of the other three males were normal, except that all had the black ground color somewhat lighter than specimens coming from unexposed pupae.

As to the systematic position of $H$. lucina, I cannot but believe that it is a distinct species, and not a subspecies of $H$. maia. The points which would support this position are as follows:

1. There are differences in the caterpillars and pupae of $H$. maia and $H$. lucina.

2. No transitions between $H$. maia and $H$. lucina have been made known.

3. The food plant of H. maia (Oak) and of H. lucina (Meadowsweet) are fundamentally different.

4. The habits of the young caterpillars are different. Those of lucina are gregarious, forming large clumps on the twigs of the food plant, while those of maia sit next to one another, in rows across the leaves.

5. Maia pupates under normal conditions in the ground, while lucina pupates between dried leaves. 
6. I am unable to account for the occurrence at the same place of H. maia as typical form with a strongly marked local form. If maia and lucina are really so closely related, we should expect crosses to take place in nature, especially as when maia males first emerge, only females of lucina are present, since the flying period of the two species overlaps only in the latter part of September. So far, however, no specimen has been found, which could be a cross between the two, that is to say, one which shows characters of both, for the individuals of both forms are always easily separated from one another. Henry Edwards has already mentioned in his description of $H$. lucina (l. c.) as a very noteworthy fact that all the specimens of maia which had come under his observation were readily known as such in spite of their considerable variability, while he was always able quickly to distinguish them from lucina.

The species and aberrations of Hemileuca occurring in the New England States would therefore be the following:

Hemileuca maia, Drury.

Hemileuca lucina Hy. Edwards.

ab. obsoleta Reiff.

$a b$. lutea Reiff. 

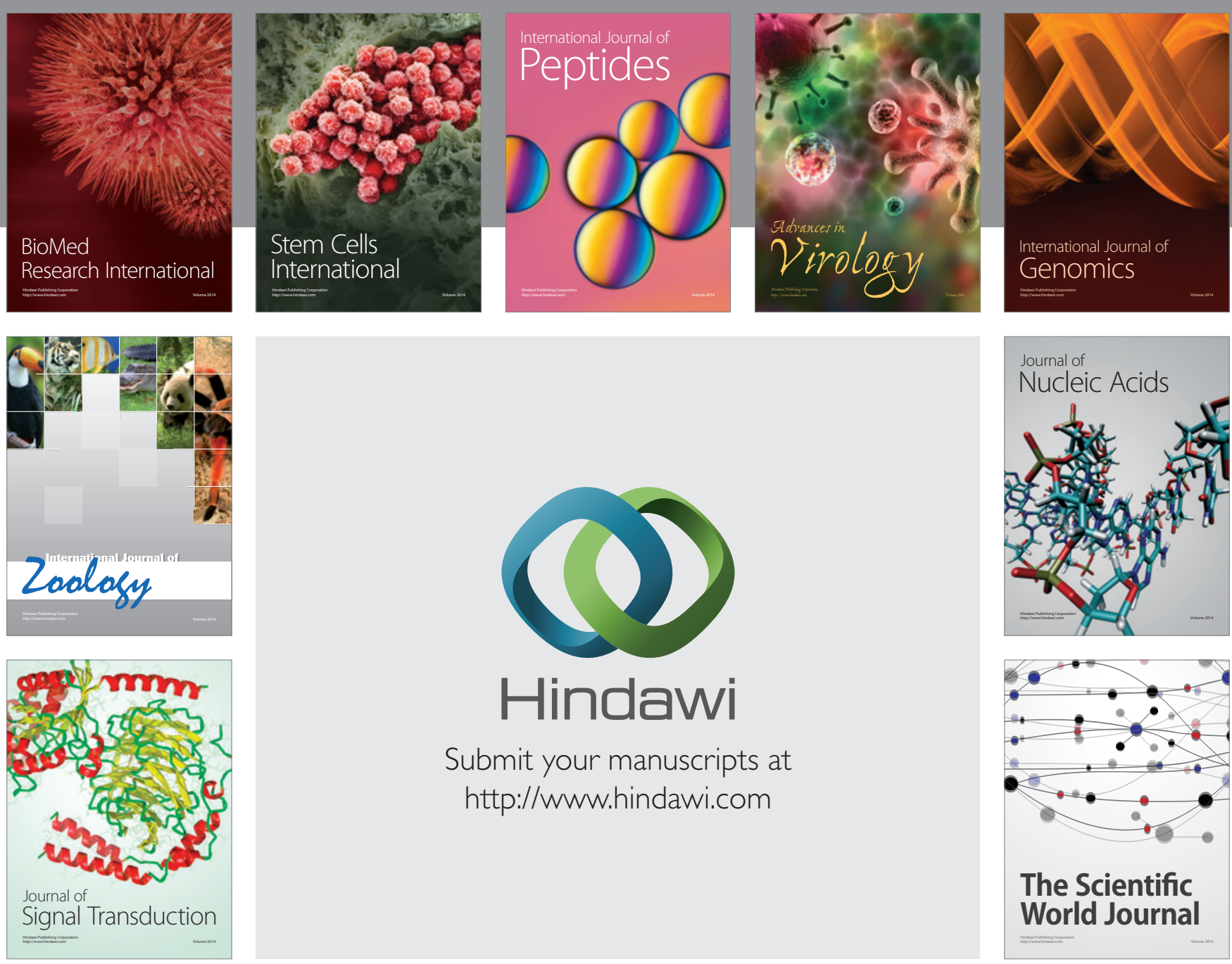

Submit your manuscripts at

http://www.hindawi.com
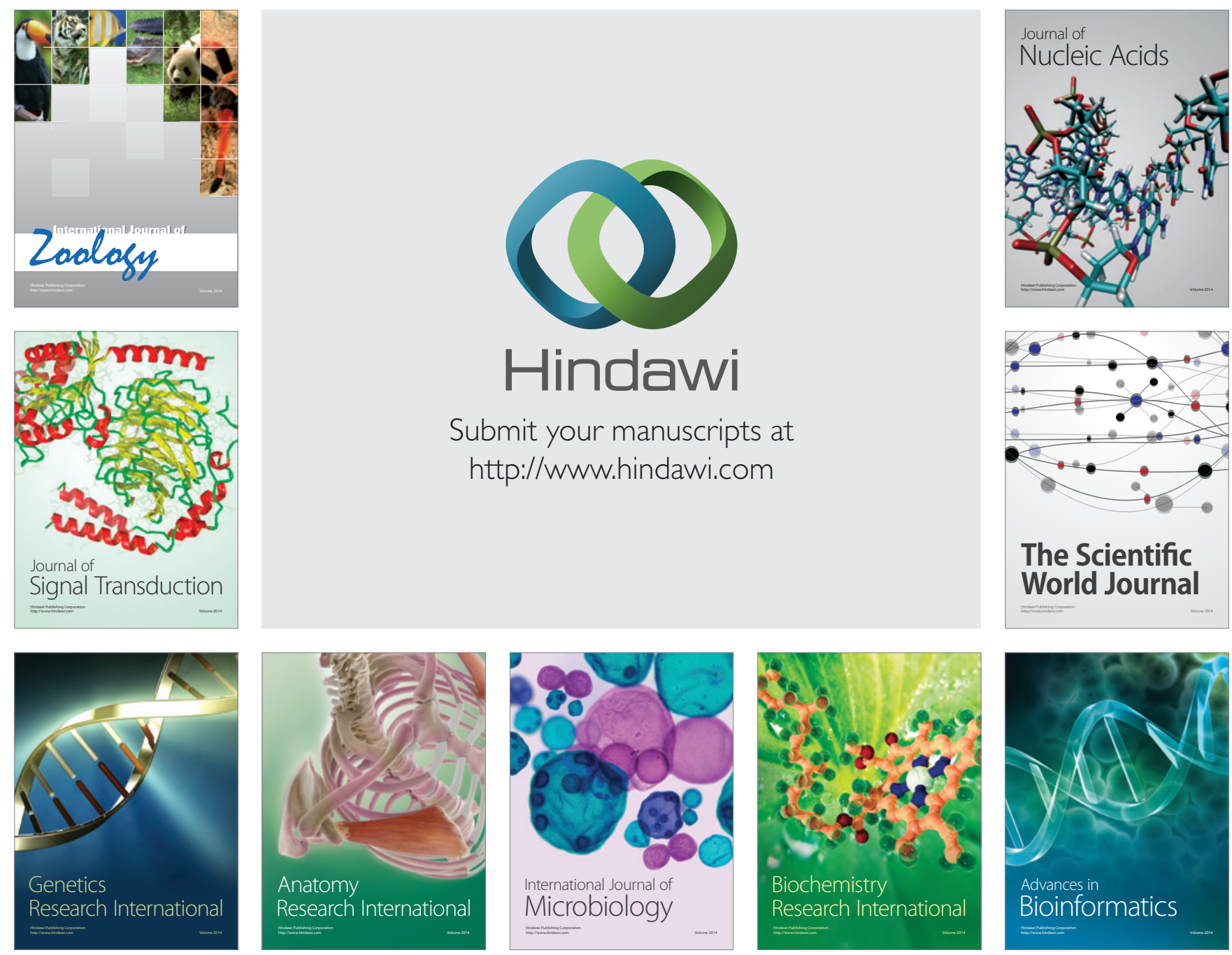

The Scientific World Journal
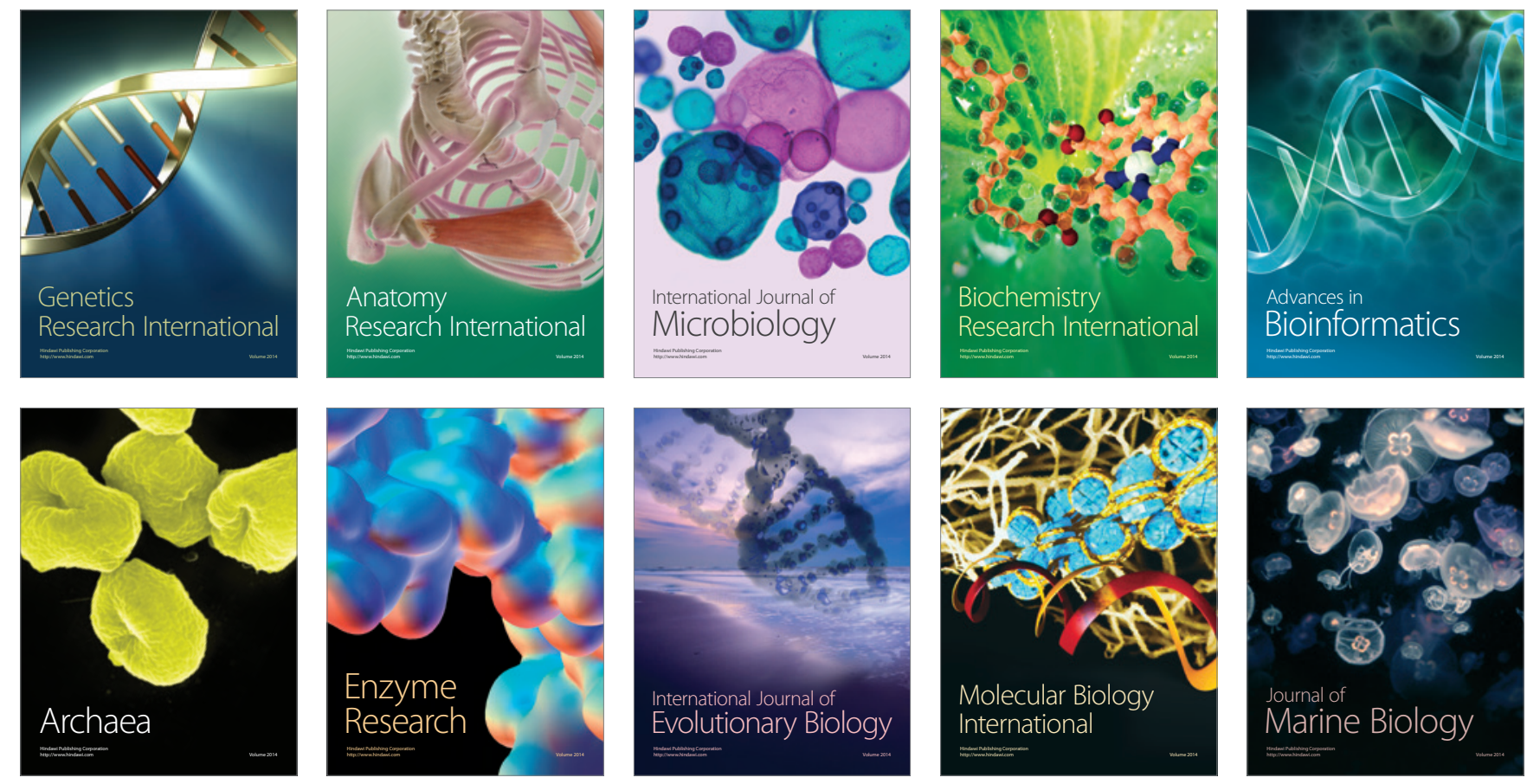